\title{
EVALUASI PERFORMASI RUANG WARNA PADA KLASIFIKASI DIABETIC RETINOPHATY MENGGUNAKAN CONVOLUTION NEURAL NETWORK
}

\author{
Candra Dewi $^{*}$, Andri Santoso ${ }^{2}$, Indriati ${ }^{3}$, Nadia Artha Dewi ${ }^{4}$, Yoke Kusuma Arbawa ${ }^{5}$ \\ 1,2,3,5 Fakultas Ilmu Komputer, Universitas Brawijaya, Malang 66145, Indonesia \\ ${ }^{4}$ Departemen Ilmu Kesehatan Mata, Fakultas Kedokteran, Universitas Brawijaya, Malang 66145, Indonesia \\ Email: 1dewi_candra@ub.ac.id, ${ }^{2}$ andrisan@ub.ac.id, ${ }^{3}$ indriati.tif@ub.ac.id, ${ }^{4}$ nadia_dewi@ub.ac.id, \\ 5yokekusumaarbawa@gmail.com \\ *Penulis Korespondensi
}

(Naskah masuk: 05 Desember 2020, diterima untuk diterbitkan: 10 Juni 2021)

\begin{abstract}
Abstrak
Semakin meningkatnya jumlah penderita diabetes menjadi salah satu faktor penyebab semakin tingginya penderita penyakit diabetic retinophaty. Salah satu citra yang digunakan oleh dokter mata untuk mengidentifikasi diabetic retinophaty adalah foto retina. Dalam penelitian ini dilakukan pengenalan penyakit diabetic retinophaty secara otomatis menggunakan citra fundus retina dan algoritme Convolutional Neural Network (CNN) yang merupakan variasi dari algoritme Deep Learning. Kendala yang ditemukan dalam proses pengenalan adalah warna retina yang cenderung merah kekuningan sehingga ruang warna RGB tidak menghasilkan akurasi yang optimal. Oleh karena itu, dalam penelitian ini dilakukan pengujian pada berbagai ruang warna untuk mendapatkan hasil yang lebih baik. Dari hasil uji coba menggunakan 1000 data pada ruang warna RGB, HSI, YUV dan L*a*b* memberikan hasil yang kurang optimal pada data seimbang dimana akurasi terbaik masih dibawah 50\%. Namun pada data tidak seimbang menghasilkan akurasi yang cukup tinggi yaitu $83,53 \%$ pada ruang warna YUV dengan pengujian pada data latih dan akurasi $74,40 \%$ dengan data uji pada semua ruang warna.
\end{abstract}

Kata kunci: diabetic retinophaty, citra fundus retina, deep learning, Convolutional Neural Network

\section{PERFORMANCE EVALUATION OF COLOR SPACE IN CLASSIFICATION OF DIABETIC RETINOPHATY USING CONVOLUTIONAL NEURAL NETWORK}

\begin{abstract}
Increasing the number of people with diabetes is one of the factors causing the high number of people with diabetic retinopathy. One of the images used by ophthalmologists to identify diabetic retinopathy is a retinal photo. In this research, the identification of diabetic retinopathy is done automatically using retinal fundus images and the Convolutional Neural Network (CNN) algorithm, which is a variation of the Deep Learning algorithm. The obstacle found in the recognition process is the color of the retina which tends to be yellowish red so that the RGB color space does not produce optimal accuracy. Therefore, in this research, various color spaces were tested to get better results. From the results of trials using 1000 images data in the color space of RGB, HSI, YUV and L*a* $b^{*}$ give suboptimal results on balanced data where the best accuracy is still below $50 \%$. However, the unbalanced data gives a fairly high accuracy of $83.53 \%$ with training data on the YUV color space and 74,40\% with testing data on all color spaces.
\end{abstract}

Keywords: diabetic retinophaty, retinal fundus image, deep learning, Convolutional Neural Network

\section{PENDAHULUAN}

Diabetic retinopathy (DR) adalah penyakit mata retinopati pada penderita diabetes yang menyebabkan kerusakan retina dan merupakan penyebab utama kebutaan. Sekitar 90\% penderita diabetic retinopathy bisa ditekan jika dilakukan deteksi dini dan pengawasan yang tepat pada mata. Menurut American Optometric Assosiation, faktor resiko penyebab DR adalah penderita diabetes tipe 1 dan tipe 2. Penelitian tentang prevalensi DR dan hubungan DR dengan kebutaan pada populasi penderita diabetes tipe 2 di Indonesian dilakukan sebelumnya (Sasongko, et al., 2017). Penelitian ini menyebutkan adanya prevelensi yang tinggi antara DR dan vision-threatening DR (VTDR) pada penduduk dewasa yang menderita diabetes tipe 2 . 
Perbandingan tersebut sekitar 1 banding 4 untuk penduduk dewasa penderita diabetes dan 1 banding 12 untuk DR dengan DVTR yang bilaterally blind.

Salah satu cara yang digunakan oleh dokter mata untuk mendeteksi adanya penyakit DR adalah menggunakan foto fundus retina. Deteksi dilakukan dengan mengamati adanya pembuluh darah yang muncul di retina. Beberapa penelitian telah dilakukan dalam upaya untuk mendeteksi DR secara otomatis menggunakan citra retina. Citra fundus mata adalah citra permukaan bagian dalam mata yang berlawanan dengan lensa dan termasuk retina, cakram optik, makula, fovea, dan kutub posterior (Cassin \& Solomon, 1990). Warna fundus bervariasi dimana pada primata memiliki retina berwarna biru, hijau, kuning, oranye, dan merah; sedangkan fundus manusia (dari orang berambut pirang ber-pigmen ringan) berwarna merah (Wolin \& Massopust, 1967).

Penelitian terkait pengenalan DR otomatis telah dilakukan menggunakan beberapa algoritma yaitu jaringan saraf multilayer (Osareh, et al., 2009)), SVM (Goatman, et al., 2011) (Kumar \& Kumar, 2018), perbandingan Gaussian Mixture Model (GMM), kNN, SVM dan AdaBoost (Roychowdhury, et al., 2014), Convolutional Neural Network atau disingkat CNN (Deperlioglu \& Köse, 2018) (Chakrabarty, 2018). Penelitian-penelitian ini menujukkan bahwa algoritme Deep Learning menggunakan CNN menghasilkan akurasi yang lebih tinggi dibandingkan dengan yang lain. Hasil pengujian CNN dengan 400 data citra diperoleh akurasi 97\%, sensitivitas 96.67\%, spesifisitas $93.33 \%$, presisi $97.78 \%$, recall $93.33 \%$, dan $F 1$ score adalah 93.33\% (Deperlioglu \& Köse, 2018). Sedangkan penelitian lain dengan $\mathrm{CNN}$ dan 30 data uji diperoleh akurasi prediksi 100\% dan sensitivitas 100\% (Chakrabarty, 2018).

Beberapa penelitian menunjukkan bahwa preproses citra masukan juga sangat berpengaruh. Penelitian oleh (Zhang, et al., 2009) melakukan filtering dalam pencocokan yang dimodifikasi untuk ekstraksi pembuluh local cross-section analysis menggunakan double-sided thresholding untuk mengurangi respons salah terhadap tepi tidak linier. Sedangkan (Osareh, et al., 2009) melakukan segmentasi citra dengan Fuzzy C-Means clustering dan seleksi fitur dengan algoritme genetik. Selanjutnya, (Goatman, et al., 2011) melakukan segmentasi kandidat vessel-like pertama-tama berdasarkan watershed lines dan ridge strength measurement. Penelitian oleh (Seoud, et al., 2016) melakukan serangkaian fitur bentuk baru, yang disebut Fitur Bentuk Dinamis. Penelitian lain oleh (Kumar \& Kumar, 2018) mendeteksi mikroaneurisma dengan principal component analysis (PCA), contrast limited adaptive histogram equalization (CLAHE), proses morfologis dan averaging filtering.
Disamping dipengaruhi oleh metode pengenalan dan proproses citra, beberapa penelitian menunjukkan adanya perbedaan hasil apabila proses dilakukan menggunakan ruang warna citra yang berbeda. Penelitian oleh (Zhang, et al., 2009), (Goatman, et al., 2011), (Akter, et al., 2014), (Seoud, et al., 2016), (Masoud, et al., 2016), (Kumar \& Kumar, 2018) menggunakan citra berwarna RGB. Selanjutnya penelitian oleh (Roychowdhury, et al., 2014) dilakukan pada lesi terang dan merah. Lalu penelitian oleh (Deperlioglu \& Köse, 2018) berbasis HSV dengan algoritma transformasi V dan teknik pemerataan histogram. Sedangkan penelitian oleh (Chakrabarty, 2018) menggunakan warna grey scale.

Penelitian-penelitian yang telah disebutkan menunjukkan bahwa penggunaan ruang warna memberikan efek dan akurasi yang bervariasi apabila diterapkan pada algoritme CNN. Bahkan penelitian (Chakrabarty, 2018) menghasilkan akurasi sampai $100 \%$ dengan menggunakan citra grey level dan sejumlah 30 data. Hasil ini lebih tinggi dibandingkan penelitian (Deperlioglu \& Köse, 2018) dengan menggunakan algoritme yang sama dan model warna HSV dengan jumlah citra 400 data. Hasil penelitian-penelitian ini juga menunjukkan bahwa semakin banyak data yang digunakan tentunya akan meningkatkan kompleksitas pengenalan. Oleh karena itu dalam paper ini diimplementasikan algoritma $\mathrm{CNN}$ dengan pengujian pengaruh berbagai macam ruang warna untuk mendapatkan ruang warna yang optimal.

\section{DATA DAN METODE PENELITIAN}

\subsection{Data}

Jenis citra fundus yang digunakan dalam penelitian ini adalah citra color fundus photography, di mana retina diterangi oleh cahaya putih dan diperiksa dalam warna penuh. Citra ini merekan informasi pembuluh darah retina yang membentuk busur di sekitar makula yang menghasilkan 20 derajat pusat penglihatan. Di tengah makula terletak fovea mungil, berukuran hanya 500 mikron. Selain merekan struktur retina, citra fundus ini juga memantau adanya gangguan dan perubahannya dari waktu ke waktu (Department of Ophthalmology and Visual Science, 2020). Citra ini dianggap baik untuk mengamati perkembangan retinopati diabetik.

Data yang digunakan dalam penelitian ini berasal dari database diabetic retinophaty yang bisa diakses di website www.kaggle.com. Keseluruhan data yang terdapat pada database ini sekitar 4000 data, namun dalam penelitian ini data yang digunakan dalam proses pelatihan dan pengujian berjumlah 1000. Data pada database ini telah diberi label sebagai groundtruth yang terdiri dari 5 kelas yaitu kela 0, 1, 2, 3 dan 4. Terdapat dua kelompok data yang digunakan dalam penelitian ini yaitu:

- kelompok 1: data dengan komposisi seimbang dengan masing-maing kelas terdiri dari 200 data 
- kelompok 2 : data dengan komposisi tidak seimbang dimana kelas 0 berjumlah 737 data, kelas 1 berjumlah 59 data, kelas 2 berjumlah 148 data, kelas 3 berjumlah 28 data dan kelas 4 berjumlah 26 data.

Citra yang ada memiliki ukuran yang bervariasi sehingga dilakukan proses resize untuk mendapatkan ukuran citra yang sama. Berdasarkan hasil uji coba awal, penggunaan citra dengan ukuran 128x128, 256x256, 512x512 dan 1024x1024 piksel tidak mempengaruhi akurasi yang dihasilkan. Namun semakin besar ukuran citra membutuhkan waktu dan kapasitas memori yang meningkat tajam pada saat pelatihan. Oleh karena itu pada penelitian ini dilakukan resize dari ukuran asli menjadi 128x128 piksel. Contoh data retina yang digunakan dalam penelitian ini ditunjukkan pada Gambar 1.

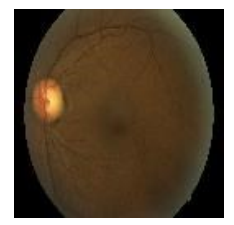

(a)

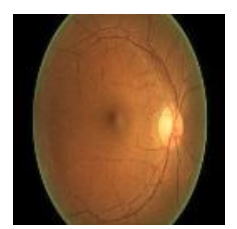

(b)

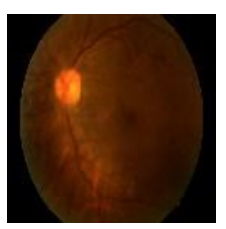

(c)
Gambar 1. Contoh citra fundus retina (a) kelas 1 (b) kelas 2 dan (c) kelas 3

\subsection{Prosedur}

Secara keseluruhan, tahapan proses klasifikasi diabetic retinophaty ditunjukkan pada Gambar 2.

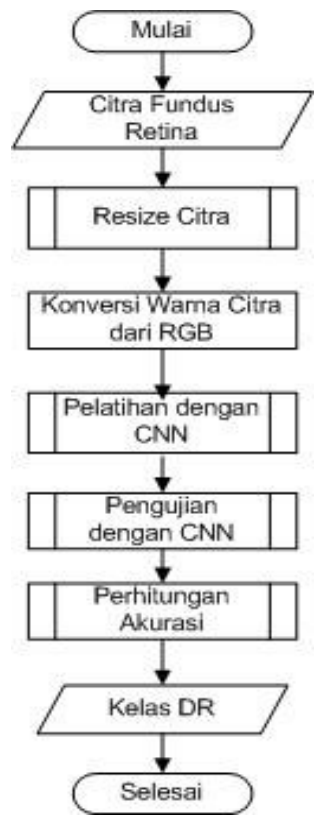

Gambar 2. Tahapan proses klasifikasi DR

Pada penelitian ini, masukan yang digunakan adalah citra fundus retina dalam ruang warna RGB. Citra masukan kemudian diproses resize untuk mendapatkan ukuran $128 \times 128$ piksel. Ruang warna dari citra dengan ukuran baru tersebut selanjutnya dikonversi dari ruang warna RGB ke ruang warna yang akan diujikan yaitu HSI, L*a*b dan YUV.
Citra yang telah dikonversi ke model warna tertentu digunakan sebagai masukan pada proses pelatihan dan pengujian menggunakan arsitektur CNN.

Pada dasarnya, arsitektur CNN sama dengan jaringan syaraf tiruan (JST) tradisional pada umumnya yang terdiri dari kumpulan neuron yang disusun pada masing-masing layer, dimana setiap neuron memiliki bobot, bias, dan fungsi aktivasi. Pada arsitektur CNN, kumpulan neuron pada setiap layer disusun secara tiga dimensi, sehingga layer pada CNN memiliki lebar, tinggi, dan kedalaman. Arsitektur CNN secara umum ditunjukkan pada Gambar 3.

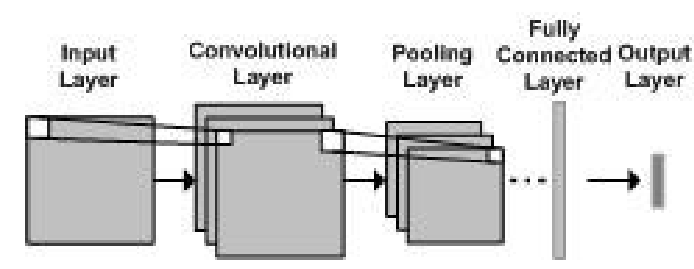

Gambar 3. Arsitektur convolutional neural network.

Proses klasifikasi pada CNN dilakukan dengan menggunakan fully-connected layer, yaitu JST dimana semua neuron disusun per layer dan saling terkoneksi satu sama lain. Untuk bisa diproses pada layer ini, maka feature map yang didapatkan pada layer konvolusi harus diratakan (flattening) sehingga menjadi sebuah vektor yang panjang dan dapat dimasukkan pada JST untuk proses klasifikasi.

Tahap pelatihan dilakukan untuk mendapatkan arsitektur jaringan terbaik dengan melakukan tuning terhadap beberapa nilai hyperparameter, yang meliputi jumlah epoch, jumlah convolution layer, ukuran filter, ukuran max pooling dan besarnya nilai drop out.

Proses pembelajaran fitur dilakukan dengan menggunakan beberapa operasi konvolusi dan pooling yang terdapat pada convolution layer dan pooling layer. Operasi-operasi tersebut digunakan untuk mengekstraksi fitur dari citra masukan. Konfigurasi suatu arsitektur CNN tidak terbatas pada penggunaan satu layer konvolusi atau pooling saja, melainkan bisa menggunakan lebih dari dua atau lebih layer. Konfigurasi jaringan yang digunakan dalam penelitian ini ditunjukkan pada Gambar 4.

\begin{tabular}{|c|}
\hline conv 32 \\
\hline conv 32 \\
\hline maxpool \\
\hline dropout \\
\hline conv 64 \\
\hline conv 64 \\
\hline maxpool \\
\hline dropout \\
\hline fullyconnected 512 + dropout \\
\hline fullyconnected 5 \\
\hline
\end{tabular}

Gambar 4. Konfigurasi jaringan CNN 
Layer pertama dari arsitektur jaringan pada penelitian ini memiliki kedalaman sebanyak tiga lapisan untuk masukan dan 32 lapisan sebagai output untuk layer selanjutnya. Hal ini disesuaikan dengan jumlah channel dari masing-masing ruang warna RGB, HSI, L*a*b dan YUV yang masing-masing memiliki 3 channel warna.

Pada penelitian ini, kumpulan filter (kernel) yang digunakan untuk operasi konvolusi pada setiap convolution layer memiliki ukuran grid sebesar 3x3 yang akan digunakan untuk menghitung konvolusi terhadap citra masukan. Sebelum dilakukan perhitungan konvolusi dari citra masukan terhadap filter, proses padding akan dikerjakan terlebih dulu terhadap citra masukan tersebut. Kemudian Rectified Linear Unit (ReLU) digunakan sebagai fungsi aktivasi yang akan menghasilkan output untuk lapisan selanjutnya. Proses perhitungan konvolusi berkaitan dengan perhitungan cross-correlation. Jika diberikan sebuah citra I dan sebuah filter $\mathrm{K}$ yang berdimensi $k_{1} \times k_{2}$, maka nilai cross-correlation dihitung menggunakan persamaan (1).

$(I \otimes K)_{i j}=\sum_{m=0}^{k_{1}-1} \sum_{n=0}^{k_{2}-1} I(i+m, j+n) K(m, n)$

Apabila diberikan citra I dan filter $\mathrm{K}$ yang sama, maka nilai konvolusi dari citra dengan filter $\mathrm{K}$ tersebut dapat dihitung menggunakan persamaan 2 .

$$
\begin{gathered}
(I * K)_{i j}=\sum_{m=0}^{k_{1}-1} \sum_{n=0}^{k_{2}-1} I(i-m, j-n) K(m, n) \\
=\sum_{m=0}^{k_{1}-1} \sum_{n=0}^{k_{2}-1} I(i+m, j+n) K(-m,-n)
\end{gathered}
$$

Persamaan (2) menunjukkan bahwa perhitungan konvolusi sama dengan perhitungan cross-correlation menggunakan kernel terbalik. Ilustrasi perkalian citra masukan dengan sebuah kernel yang tidak dibalik dapat dilihat pada Gambar 5.

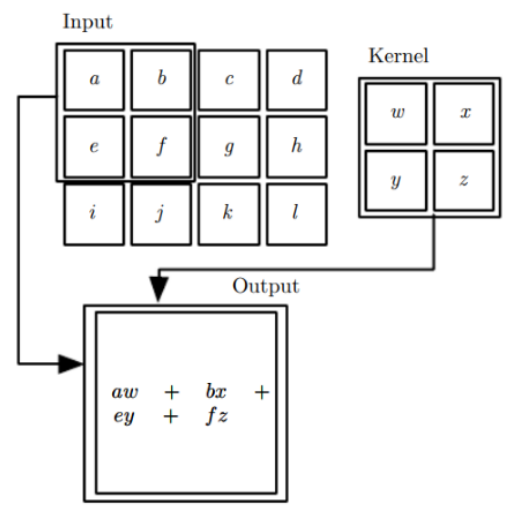

Gambar 5. Ilustrasi dari perhitungan konvolusi dengan kernel yang tidak dibalik

Proses konvolusi dari citra $I$ dan kernel $K$ menghasilkan feature map, yang selanjutnya akan diproses pada pooling layer. Lapisan pooling terletak diantara layer konvolusi yang satu dengan layer konvolusi yang lain. Secara bertahap, pada poling layer dilakukan penggurangan dimensi dari representasi fitur yang ada pada layer konvolusi. Adapun dalam penelitian ini digunakan max pooling, dimana nilai yang dikembalikan adalah nilai maksimum dari area pada citra yang terlapisi kernel, dan dapat dihitung menggunakan persamaan 3 .

$h_{x y}^{l}=\max _{i=0 . . s, i=0 . . s} h_{(x+i)(y+j)}^{l-1}$

Proses dilanjutkan dengan pengujian $\mathrm{CNN}$ pada arsitektur terbaik yang diperoleh dari proses pelatihan dan dengan data uji yang tidak digunakan sebagai data pelatihan. Untuk mengetahui tingkat keberhasilan algoritme, maka pada tiap pengujian dilakukan perhitungan akurasi dengan membandingkan data yang diklasifikasikan benar dengan keseluruhan data yang diuji.

Proses pelatihan dan pengujian dilakukan untuk keempat model warna dan akurasi dari tiap model warna dibandingkan untuk mengetahui model warna mana yang memberikan hasil terbaik.

\section{HASIL DAN PEMBAHASAN}

Pada penelitian ini dilakukan pengujian pada ruang warna RGB, HSI, YUV dan L*a*b*. Pengujian dilakukan pada komposisi kelas seimbang dan tidak seimbang. Pertimbangan dilakukan pengujian dengan komposisi kelas seimbang dan tidak seimbang ini setelah melakukan pelatihan dengan data seimbang dimana diperoleh hasil yang kurang memuaskan. Dengan demikian perlu dilakukan uji-coba dengan data tidak seimbang Keseluruhan data terdiri dari 1000 yang terbagi menjadi $75 \%$ data latih dan $25 \%$ data uji. Keseluruhan pelatihan dilakukan pada arsitektur jaringan sebagai berikut:

- Jumlah epoch : 150

- Konvolusi awal : 32

- Jumlah konvolusi : 3 kali (32, 64 dan 64)

- Ukuran filter : 3 x 3

- Max pooling : $2 \times 2$

- Drop out : $25 \%$

- Fungsi aktivasi : Relu

- Solver : Adam

Arsitektur ini dipilih setelah dilakukan beberapa kali pelatihan untuk mendapatkan arsitektur yang optimal. Perkembangan akurasi pada proses pelatihan dengan komposisi kelas tidak seimbang pada ruang warna RGB ditunjukkan pada Gambar 6.

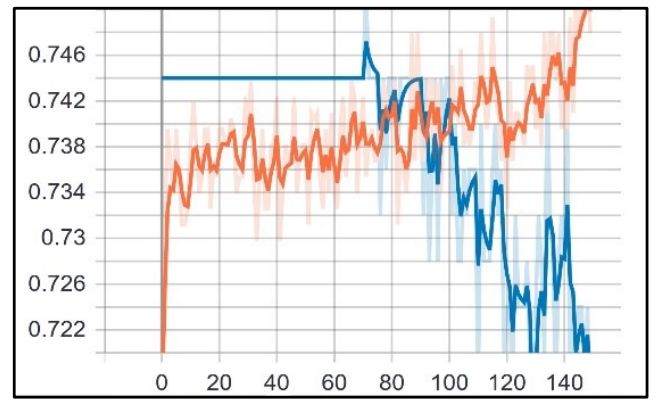

Gambar 6. Perubahan nilai akurasi data training dan testing 
Pada Gambar 6 terdapat dua garis yaitu merah dan biru, dimana merah menunjukkan perkembangan pelatihan dengan data latih, sedangkan biru menunjukkan perkembangan pelatihan dengan data validasi. Dari gambar ini dapat diketahui bahwa nilai akurasi dengan data latih cenderung naik, namun nilai akurasi pengujian mengalami penurunan setelah epoch ke 60 .

\subsection{Pengujian pada Data Seimbang}

Hasil pengujian pada data seimbang pada berbagai ruang warna ditunjukkan pada Tabel 1Error! Reference source not found. Dari Tabel 1 terlihat bahwa hasil pengujian pada data seimbang menghasilkan akurasi yang rendah. Akurasi tertinggi dengan data latih adalah $55,08 \%$ pada ruang warna RGB, sedangkan dengan data uji adalah 26,51 juga pada ruang warna $\mathrm{L}^{*} \mathrm{a}^{*} \mathrm{~b}^{*}$. Dari tabel juga terlihat bahwa penggunaan ruang warna yang berbeda tidak memberikan perbedaan hasil yang siknifikan pada data testing.

\begin{tabular}{ccc}
\multicolumn{2}{c}{ Tabel 1. Hasil pengujian pada data seimbang } \\
\hline \multirow{2}{*}{ Ruang Warna } & \multicolumn{2}{c}{ Akurasi (\%) } \\
\cline { 2 - 3 } & Data Training & Data Testing \\
\hline RGB & 55.08 & 25,30 \\
HSI & 28,20 & 23,69 \\
L*a*b* & 40,61 & 26,51 \\
YUV & 35,17 & 24,90 \\
\hline
\end{tabular}

Secara lebih detail, contoh kesalahan pengenalan pengujian data seimbang pada ruang warna $\mathrm{L}^{*} \mathrm{a} * \mathrm{~b} *$ ditunjukkan pada Tabel 2. Dari pengujian terhadap 249 data uji, terlihat bahwa hanya 65 data yang dikenali benar atau sesuai dengan kelasnya, 126 data target yang dikenali tidak sesuai dengan kelasnya (true negatif) dan 58 data dikenali sebagai missing data (false positif).

Dati Tabel 2 juga dapat diketahui bahwa persentase tiap kelas dapat dikenali benar sangat rendah yaitu hanya berkisar $25 \%$ sampai dengan $37 \%$. Dari hasil pengamatan diketahui bahwa data antara kelas yang satu dengan yang lain memiliki kemiripan fitur yang tinggi. Hal inilah yang mengakibatkan proses klasifikasi gagal mengenali kelas yang ada secara benar.

Tabel 2. Matrik confussion pengujian data seimbang pada ruang warna $\mathrm{L}^{*} \mathrm{a} * \mathrm{~b}$

\begin{tabular}{|c|c|c|c|c|c|c|}
\hline & & \multicolumn{5}{|c|}{ Prediksi } \\
\hline & & $\mathbf{0}$ & 1 & 2 & 3 & 4 \\
\hline \multirow{5}{*}{ 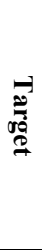 } & $\mathbf{0}$ & 16 & 11 & 10 & 1 & 5 \\
\hline & 1 & 17 & 17 & 3 & 6 & 3 \\
\hline & 2 & 21 & 10 & 10 & 10 & 5 \\
\hline & 3 & 13 & 12 & 5 & 17 & 4 \\
\hline & 4 & 15 & 11 & 13 & 9 & 5 \\
\hline
\end{tabular}

\subsection{Pengujian pada Data Tidak Seimbang}

Hasil pengujian pada data tidak seimbang ditunjukkan pada Tabel 3. Hasil pengujian menggunakan data tidak seimbang memberikan hasil yang lebih baik dibandingkan dengan data seimbang. Akurasi tertinggi yang diperoleh menggunakan data latih adalah $83,53 \%$ pada ruang warna YUV. Pada pada uji memiliki akurasi yang hampir sama pada setiap pengujian, dimana akurasi tertinggi yang diperoleh adalah adalah $74,40 \%$ pada semua ruang warna.

Tabel 3. Hasil pengujian pada data tidak seimbang

\begin{tabular}{ccc}
\hline \multirow{2}{*}{ Ruang Warna } & \multicolumn{2}{c}{ Akurasi (\%) } \\
\cline { 2 - 3 } & Data Training & Data Testing \\
\hline RGB & 76,00 & 74,40 \\
HSI & 73,73 & 74,40 \\
L*a*b* & 73,80 & 74,40 \\
YUV & 83,53 & 74,40 \\
\hline
\end{tabular}

Hasil pengujian data tidak seimbang pada ruang warna YUV secara lebih detil ditunjukkan pada Tabel 4. Dari 250 data yang diuji terlihat bahwa hampir semua data yang dikenali benar adalah kelas 0 dengan jumlah 186 data. Sedangkan untuk kelas yang lain hampir semua target tidak dikenali dengan benar (true negatif), dimana semua data dikenali sebagai kelas 0. Dari pengamatan terhadap fitur data, diketahui bahwa nilai fitur dari kelas 1 sampai 4 mendekati sama bahkan dengan kelas 0 . Dengan semakin banyaknya variasi data di kelas 0, mengakibatkan kelas ini semakin dominan dan data uji dari kelas lain dikenali kelas 0 .

Tabel 4. Matrik confussion pengujian data tidak seimbang pada ruang warna YUV

\begin{tabular}{ccccccc}
\hline & \multicolumn{5}{c}{ Prediksi } \\
\cline { 2 - 7 } & $\mathbf{0}$ & $\mathbf{1}$ & $\mathbf{2}$ & $\mathbf{3}$ & $\mathbf{4}$ \\
\hline & $\mathbf{0}$ & 186 & 0 & 0 & 0 & 0 \\
\hline \multirow{2}{*}{$\mathbf{0}$} & $\mathbf{1}$ & 11 & 0 & 0 & 0 & 0 \\
& 38 & 0 & 0 & 0 & 0 \\
\hline & 6 & 9 & 0 & 0 & 0 & 0 \\
\hline
\end{tabular}

Dari hasil pengujian terhadap data seimbang dan tidak seimbang diketahui bahwa penggunaan data tidak seimbang menghasilkan akurasi yang lebih baik. Setelah diamati ternyata hampir semua yang dideteksi benar adalah kelas 0. Dengan kata lain menunjukkan bahwa hampir semua kesalahan klasifikasi adalah pada kelas 1 sampai 4 dengan gejala retinophaty. Seperti disampakan sebelumnya bahwa pada gambar retina terlihat bahwa kelas 1 sampai 4 memiliki pola citra yang hampir sama, sehingga proses konvolusi tidak dapat dilakukan secara optimal untuk mengenali perbedaan yang ada. 
Pada CNN, semakin dalam proses konvolusi maka akan menghasilkan citra dengan tingkat blur yang semakin tinggi sehingga membuat bagian citra semakin terlihat kurang jelas. Proses rezise untuk mengecilkan resolusi citra tentunya juga dapat mempengaruhi kedetilan citra, sehingga semakin dalam konvolusi juga mengakibatkan informasi juga semakin kurang optimal. Penggunaan ruang warna YUV meskipun cukup berhasil pada proses pelatihan, namun pada saat pengujian menghasilkan nilai yang sama dengan ruang warna yang lain. Hal ini menunjukkan perlu dilakukan preproses terlebih dahulu sebelum dilakukan konvolusi agar bagianbagian tertentu memiliki kontras yang lebih baik. Dengan demikian akan lebih memudahkan dalam mendeteksi adanya perdarahan yang terjadi di pembuluh darah retina, lesi pucat seperti drusen dan eksudat, dan karakteristik lain yang menyebabkan terjadinya DR.

\section{KESIMPULAN}

Pada penelitian ini dilakukan pengujian penggunaan ruang warna RGB, HSI, L*a*b dan YUV untuk mengetahui ruang warna yang optimal pada proses identifikasi DR. Berdasarkan pengamatan pada proses pelatihan menggunakan komposisi kelas seimbang, diperoleh hasil yang kurang baik sehingga dilakukan pengujian lanjutan menggunakan komposisi kelas tidak seimbang. Dari hasil pengujian menggunakan 1000 data dengan komposisi data seimbang dan data tidak seimbang dapat diketahui bahwa pemilihan ruang warna menghasilkan akurasi yang kurang optimal untuk data seimbang, namun untuk data tidak seimbang diperoleh hasil yang cukup tinggi yaitu $85,53 \%$ pada data latih dengan menggunakan ruang warna YUV dan $74 \%$ pada data uji untuk semua ruang warna.

\section{DAFTAR PUSTAKA}

AKTER, M., UDDIN, M. S. \& KHAN, M. H., 2014. Morphology-based exudates detection from color fundus images in diabetic retinopathy. Dhaka, Bangladesh, IEEE International Conference on Electrical Engineering and Information \& Communication Technology.

CASSIN, B. \& SOLOMON, S., 1990. Dictionary of Eye Terminology. Gainesville, Florida: Triad Publishing Company.

CHAKRABARTY, N., 2018. A Deep Learning Method for the detection of Diabetic Retinopathy. Gorakhpur, India, 5th IEEE Uttar Pradesh Section International Conference on Electrical, Electronics and Computer Engineering (UPCON).

DEPARTMENT OF OPHTHALMOLOGY AND VISUAL SCIENCE, C. C. O. M., 2020. ophthalmology.med.ubc.ca. [Online] Available at: Available: https:// medicine.uiowa.edu/eye/ patient-care/imaging-services/color-fundusphotography. [Diakses October 2019].

DEPERLIOGLU, Ö. \& KÖSE, U., 2018. Diagnosis of Diabetic Retinopathy by Using Image Processing and Convolutional Neural Network. Ankara, Turkey, IEEE 2nd International Symposium on Multidisciplinary Studies and Innovative Technologies (ISMSIT).

GOATMAN, K. A. et al., 2011. Detection of New Vessels on the Optic Disc Using Retinal Photographs. IEEE Transactions on Medical Imaging, 30(4), p. 972 - 979.

KUMAR, S. \& KUMAR, B., 2018. Diabetic Retinopathy Detection by Extracting Area and Number of Microaneurysm from Colour Fundus Image. Noida, India, IEEE 5th International Conference on Signal Processing and Integrated Networks (SPIN).

MASOUD, A.-S., POURREZA, H. R. \& BANAEE, T., 2016. A Novel Curvature-Based Algorithm for Automatic Grading of Retinal Blood Vessel Tortuosity. IEEE Journal of Biomedical and Health Informatics, 20(2), p. 586 - 595.

NG, E. . Y. K., ACHARYA, U. R., RANGAYYAN, R. M. \& SURI, J. S., 2020. Ophthalmological Imaging and Applications. United States: CRC Press, Inc.

OSAREH, A., SHADGAR, B. \& MARKHAM, R., 2009. A Computational-Intelligence-Based Approach for Detection of Exudates in Diabetic Retinopathy Images. IEEE Transactions on Information Technology in Biomedicine, 13(4), p. 535 - 545.

ROYCHOWDHURY, S., KOOZEKANANI, D. D. \& PARHI, K. K., 2014. DREAM: Diabetic Retinopathy Analysis Using Machine Learning. IEEE Journal of Biomedical and Health Informatics, 18(5), p. $1717-1728$.

SASONGKO, M. B. et al., 2017. Prevalence of Diabetic Retinopathy and Blindness in Indonesian Adults With Type 2 Diabetes. American Journal of Ophthalmology, Volume 181, pp. 79-87.

SEOUD, L. et al., 2016. Red Lesion Detection Using Dynamic Shape Features for Diabetic Retinopathy Screening. IEEE Transactions on Medical Imaging, 35(4), p. $1116-1126$.

WOLIN, L. R. \& MASSOPUST, L., 1967. Characteristics of the ocular fundus in primates. Journal of Anatomy, 101(4), p. 693699.

ZHANG, L., LI, Q., YOU, J. \& ZHANG, D., 2009. A Modified Matched Filter With Double-Sided Thresholding for Screening Proliferative Diabetic Retinopathy. IEEE Transactions on Information Technology in Biomedicine, 13(4), p. $528-534$. 